\title{
Reconciling End-to-End and Population Concepts for Marine Ecosystems
}

\section{John H. Steele and Dian J. Gifford}

\begin{abstract}
$\underline{\text { Abstract }}$
The inherent complexities in the structure and dynamics of marine food webs have led to two major simplifying concepts, a species-centric approach focused on physical processes driving the population dynamics of single species and a trophic-centric approach emphasizing energy flows through broad functional groups from nutrient input to fish production. Here we review the two approaches and discuss their advantages and limitations. We suggest that these concepts are complementary: their applications involve different time scales and distinct aspects of population and community resilience, but their integration is necessary for ecosystem-based management
\end{abstract}

Key words: $\quad$ marine ecosystem, energy flow, food webs, resilience

John H. Steele, Woods Hole Oceanographic Institution, Woods Hole MA, 02543, jsteele@whoi.edu

Dian J. Gifford

Graduate School of Oceanography, University of Rhode Island, Narragansett, RI 02882, USA.; dgifford@gso.uri.edu 
Corresponding author: Dr John Steele

Marine Policy Center, Woods Hole Oceanogr. Instn.

Woods Hole, MA 02543, USA

Tel 5082892220 Fax 5084572184

\section{Introduction}

The close coupling of physical dynamics and ecological processes is a defining feature of marine ecosystems (Steele, 1985; Wiebe et al, 2001). Analysis of these relationships has generally followed two approaches: focus on the direct effects of physical processes at the individual species or population level versus focus on indirect effects through physical control of nutrient availability and transmission up the food web to top predators. The first, species-centric approach takes advantage of major advances in modeling advection and mixing in environments with complex topography. Here physical models are combined with simple formulations of the lower trophic levels or with descriptions of individual populations of pelagic species. This approach, depicting the non-linear dynamics of a few food web components, is the basis for the successful JGOFS (Joint Global Ocean Flux Study) and GLOBEC (Global Ocean Ecosystems) modeling programs. The use of detailed simulations of spatial dynamics requires some limitation on biology and led de Young et al (2004) to propose that "rather than model the entire ecosystem we should focus on key target species and develop species-centric models". In the second, trophic-centric, approach analysis focuses on the overall processes within food webs from nutrient uptake to 
fish production. On continental shelves the close coupling between pelagic and benthic food webs (Steele and Collie 2005) determines the structure of higher trophic levels. The diverse trophic components, with their large range in time scales and complicated links within the food web, pose quite different challenges to modelers, including accounting for the direct effects of mixing and transport on individual organisms.

Past food web studies have tended to treat the upper and lower trophic levels separately, and for different purposes. The microbial web in the open ocean was studied intensively in the JGOFS program (e.g., Buesseler 2001) where the focus was on export of carbon, defined as downward transport out of the euphotic zone. For studies emphasizing the upper trophic levels, the focus is on predatory interactions based on fish diet data (Garrison and Link 2000; Heath 2005). Linear, steady-state, food-web models have been used to encompass these complex interactions (Christensen \& Pauly 1993). This trophic-centric approach does not include the dynamics of individual species. Recently, in response to the desire for ecosystembased management, end-to-end models combining bottom-up and top-down components have been used to portray continental shelf ecosystems (Aydin et al. 2005: Steele et al. 2007 ).

The "horizontal", species centric, approach proposed by de Young et al (2004) emphasizes the processes that link individual species or single trophic guilds directly to their physical environment. The "vertical" trophic-centric approach focuses on the 
flux of nutrients from inorganic states to the upper levels of the food web and can use complicated optimizations with large matrix inversions to resolve fluxes in linear steady state systems (Vezina \& Platt 1988). The former has complex physical processes and relatively simple population dynamics; the latter combines complicated food webs with linear steady state descriptions of processes.

In this paper, we illustrate the two approaches from work on the Georges Bank ecosystem. We argue that there are no contradictions between the two sets of simplifying assumptions. They are complementary and answer different questions about the dynamics of individual populations and the productivity of trophic communities. We review briefly some other methods that can be categorized as focusing on species or community structure. The relevant issue is the extent to which these methods, jointly, can illuminate the concept of ecosystem-based management; and how they can be combined to answer questions about short- and long-term conservation of marine resources.

\section{A case study: Georges Bank}

The problem of reconciling the species-centric and trophic-centric approaches can be illustrated from studies of Georges Bank. Detailed simulations of the anti-clockwise circulation around the Bank describe the transport of cod and haddock larvae from spawning sites on the north-east peak to potentially rich food on the southern flank of the Bank, Fig. 1 (Werner et al 1996; Lynch et al 2001). Larval growth rates are 
correlated with copepod abundance, particularly Pseudocalanus spp. (Buckley \& Durbin 2006), but not with years of successful recruitment to the adult stocks. These studies demonstrate the way that broadcast spawners have evolved by adapting to the regularities in their physical environment. But the complexities in such processes and their inter-annual variability explain why very few environment-recruitment correlations survive re-examination (Myers 1998). The only exceptions are for populations located at the latitudinal extremes of their range (Drinkwater 2005). Friedland et al (2008) proposed that successful recruitment of Georges Bank haddock depends on the food available to the adult spawners the previous fall, but this has been challenged (Payne et al 2009). This controversy exemplifies the problems with the assumption that "recruitment" processes in the larval phase determine the year class strength of individual species (Rothschild, 1986) and with the hope that information about the physical system can predict future stocks (Myers 1998).

A general problem with studies of declines in gadoid stocks such as cod, are the corresponding increases in other stocks - elasmobranchs followed by pelagic species on Georges Bank, Fig. 2; crustaceans on the Newfoundland and Nova Scotia continental shelves (Worm and Myers 2003); and small pelagic fish in the North Sea (Heath, 2005). Some possible explanations of these patterns are phrased in terms of “cascades" (Frank et al. 2005) or "regime shifts" (Choi et al. 2004). These studies rely on comparisons or correlations of time series of a few selected species and do not consider the energetic implications of changes in the entire trophic web. 
The alternative trophic-centric approach quantifies fluxes of energy, nutrients or carbon through the entire food web (Steele 1974; Vezina and Platt 1988; Heath 2005). For Georges Bank, seminal studies were done by Sissenwine and colleagues (Cohen et al. 1982; Sissenwine et al. 1984). More recently Steele et al. (2007) combined data on the fish community and its diet (Garrison \& Link 2000), with detailed analyses of the microbial food web beginning with uptake of $\mathrm{NO}_{3}$ (Bisagni 2003) to determine end-to-end fluxes, Fig. 3. The model output was expressed in terms of production by three trophic guilds of fish - planktivores, benthivores and piscivores - described by the major components of their diet. Thus a critical physical constraint, flux of $\mathrm{NO}_{3}$, determines the total abundance of the adult fish stocks in broadly defined communities but does not determine abundance of individual species such as cod or haddock.

This issue is illustrated by the response of the Georges Bank fish community to changes in ocean climate and fishing effort. There were two major stresses, decreased production during 1963-1972, and very high fishing effort during 1967-1976 (Fig. 2a). The lower levels of total production, connected to lower nutrient input, are associated with negative NAO and a strengthening of the Labrador Current (Pershing et al. 2001). Diversity indices responded rapidly to the removal of the stresses after 1976 (Gifford et al. 2009), exemplified by the change in the evenness index (Fig. 2b). There were also major changes in the fraction of benthos in fish diet (Fig. 2c). These relatively regular patterns contrast markedly with fluctuations in the dominant species in the demersal and pelagic fish guilds, which varied greatly over the succeeding 
three decades (Fig. 2c,d). Some of the species succession may be interpreted as a response to reduction in fishing effort after 1976 (Fig. 2a). These results from the Georges Bank ecosystem indicate that longer-term system organization may reside at the community rather than the species level. This led Gifford et al. (2009) to propose that the changes in species composition demonstrated the resilience of the food web to the removal of these combined climatic and fishing stresses.

\section{Analysis}

Attempts to combine complex physical processes with a large number of interacting populations specified by details of their demography, are often not useful or comprehensible, even when technically possible (deYoung et al. 2004). It is necessary to simplify some components of these coupled physical-chemical-biological systems. The Georges Bank studies epitomize general distinctions between approaches with different simplifying assumptions and trade-offs that can be categorized as speciescentric and trophic-centric (Table 1). These two approaches make different judgments about the interest or significance of certain aspects of marine systems. The speciescentric approach focuses on individual species (de Young et al. 2004). At higher trophic levels we have extensive use of age-structured models to estimate maximum sustainable yield (MSY) of commercially important fish species. These calculations assume there is a "surplus yield" (Rothschild 1986) that is independent of the remainder of the food web. There is the general assumption that the "recruitment" processes of each species that determine year class strength are dictated 
predominantly by physical transport of the larvae to areas with adequate food (Buckley and Durbin 2006). In contrast, the trophic-centric approach emphasizes the constraints imposed on large trophic groups of species by overall food supply that, in turn, is determined by nutrient fluxes. For the fish components of the food web, the method assumes implicitly that the significant component is the abundance of adults in the trophic groups.

The two approaches are sufficiently distinct to be regarded as two separate hypotheses about critical factors for marine communities. One is related to dynamics of individual species and the other to abundance of trophic groups. The former focuses on variability of larval survival as the critical population factor while the latter considers the adult food requirements of communities as the main constraint. One approach attempts to determine the causes of inter-annual variability; the other stresses the probable causes of decadal changes. The two approaches are not unconnected. For Georges Bank a critical factor for individual fish larvae is the residence time of upper layers of the water column on the Bank (Werner et al, 1996). Residence time determines, in turn, the influx of deeper nutrient rich water that fuels overall production (Steele et al, 2007). For fish population dynamics, the mortality pattern of juveniles is a major unknown factor (Houde, 1996). This is a problem both for the links between larval and adult numbers for individual species (Rothschild, 1986) and for calculation of the total food requirement of fish communities (Sissenwine et al, 1984; Steele et al, 2007: Heath, 2007). There is no reason why both sets of critical factors may not operate together as constraints on individual 
populations and on communities. Our interest, as consumers, is in the maintenance of individual species at some appropriate level of abundance; and as ecologists in the sustainability of communities. How far can these two sets of assumptions and methodologies combine these interests?

\section{Discussion}

Comparison of trophic- and species-centric concepts is intended to highlight the advantages and constraints inherent in these two approaches to ecosystem organization. These forms of analysis may be regarded as the end points of an array of methods (Table 1). The original three variable NPZ model has expanded to systems with multiple N, P and Z, but for these highly non-linear dynamic systems there are costs as well as benefits in going from 4 to11 state variables (Friedrichs $e t$ al. 2007). Linear steady state models such as ECOPATH generally have 20 to 60 compartments. The question is: how to reconcile these two quite distinct concepts?

One possibility is to combine them in a single model, for example in a system such as ATLANTIS (Fulton et al, 2004) that contains spatial structure, horizontal advection, vertical mixing, components from nutrients to fish, and non-linear dynamics. ATLANTIS has hundreds of parameters (see Plaganyi (2007) for a thorough and informative review of "methods for an ecosystem approach to fisheries"). The application of this model can be limited by the heavy demands on data (Plaganyi 
2007). There are similar concerns (Plaganyi and Butterworth 2004; Koen-Alonso and Yodzis 2005) with ECOSIM, the non-linear extension of ECOPATH (EwE, Walters et al. 1997). One alternative to such large integrated systems links models of different parts of the food web for an end-to-end representation. Aydin et al (2005) combined an NPZ model of the lower food web with an ECOPATH budget that, in turn forces a demographic model of Pacific salmon. Heath et al (1997) use ERSEM II (BarettaBecker and Baretta, 1997), a lower trophic model of the North Sea, to drive the demographics of different herring stocks. The problem with such constructs is the limitation or lack of feedback between model components.

There has been a revival of interest in size-based portrayals of prey-predator relations as an alternative to food web structure within fish communities (Hall et al 2006; Pope et al 2006). These have the advantage of simulating virtual "species", defined by initial and final lengths and length at maturity, without requiring specific names. These analyses do not attempt to cover all trophic levels as did some earlier models (Platt and Denman, 1978; Kerr and Dickie, 2001), but their output can depict theoretical size/biomass relations similar, in principle, to trophic scaling. To illustrate this similarity, we compare percentage abundance in terms of three fish size categories (small, medium and large) in the Georges Bank ecosystem (Fig. 4a) derived from the asymptotic lengths of the 21 species used in Hall et al. (2006), with the relative abundances expressed in terms of 35 species allocated to feeding guilds (Fig. 4b). The similarity is striking, but not unexpected, given the nature of each group. The major planktivore and piscivore species are located predominantly in the 
small and large categories respectively, with the benthivores intermediate. Thus the two methods of "vertical" analysis, trophic-web and size-based, share a common representation of fish community structure for Georges Bank at least.

The methods considered so far have one feature in common - they are all deterministic. An entirely different approach to community structure describes the statistical properties of communities and portrays regularities in pattern in terms of diversity indices. At the community level there is particular interest in, and data on, fish stocks. The general structure of fish communities can be described in different ways. For Georges Bank we have used prey-predator relations to describe the energy flow and determine the productivity of different trophic groups including diet-based fish guilds. Diversity indices relate more to competitive interactions (Hubbell, 1997) and convey relatively little information about system productivity. They depict different features of the community responses that appear to reflect the overall community resilience (Tilman, 1999) and this is observed on Georges Bank (Fig. 2b; Gifford et al, 2009).

The concepts of size structure and diversity share an important feature in commen with the trophic-centric approach: information about productivity or resilience occurs at the community, rather than the population, level of organization. As Nicholson and Jennings (2004) point out, "while community metrics do provide good long term indicators of changes in fish community structure, they are unlikely to provide an appropriate tool to support short term management decisions". The critical issue for 
research planning, but especially for advice to management, is how to bridge the gap between shorter-term stock forecasts for individual stocks required by managers, and longer term assessments of community production and resilience. At present, to combine the trophic and the species centric concepts, we have a choice between very large integrated systems, or relatively idiosyncratic combinations of different types of models. A particular concern is that all these different representations of large food webs have not been subject to the skill assessments applied to biogeochemical methods (Friedrichs et al, 2007) and to coupled physical-biological models ( Lynch et al 2009). We do not have any measure of their relative performance and so no guidance on how to select among them. Such assessments are necessary if we are to develop a coherent approach to ecosystem-based management.

There are three unresolved problems; the links between larval and adult abundance; the relations between population and community dynamics; and the transition from inter-annual to inter-decadal. A null hypothesis is that, in the longer term, recruitment of individual species is a lottery (Sale 1977) constrained by production and competition at the community level (Yachi and Loreau 1999). The distinction between population and community processes is rather like, and possibly related to, the distinction between weather and climate. On this basis, increased insight into physical/ biological coupling or greater knowledge of species diets for intermediate food web components could allow us to make medium term predictions of yields for individual species. 
Resolution of these questions will require a greater appreciation of the basic ecological problems involved in the relations between the concepts of productivity of individual species, diversity of communities, and resilience of ecosystems; how we represent these interactions in models of marine systems; and how we relate them to management of our marine environment (May 1973; Lehman and Tilman 2000; Murawski et al 2009).

\section{Acknowledgements}

This article is a development and expansion of a preliminary report in the GLOBEC International Newsletter (October 2007). We acknowledge NOAA-CICOR award NA17RJ1233 (J.H. Steele) and NSF award OCE0217399 (D.J. Gifford). We thank M.J. Fogarty for the provision of data and J.S. Collie for helpful discussions. Contribution number xxx of the US-GLOBEC Georges Bank Program.

\section{$\underline{\text { References }}$}

Aydin, K.,. McFarlane, G.A., King, J.R., Megrey, B.A. and Myers K.W.. 2005. Linking oceanic food webs to coastal production and growth rates of Pacific salmon 
(Oncorhynchus spp.), using models on three scales. Deep Sea Research, II, 52, 757780.

Baretta-Becker, J., Baretta, J., Ebenhoh, W. 1997. Microbial dynamics in the marine ecosystem model ERSEM II. 38, 195-211.

Bisagni, J.J. 2003. Seasonal variability of nitrate supply and potential new production in the Gulf of Maine and Georges Bank regions. Journal of Geophysical Research, 108, c11, 8015 .

Buckley, L.J. and Durbin, E.G. 2006. Seasonal and inter-annual trends in the zooplankton prey and growth rate of Atlantic cod (Gadus morha) and haddock (Melanogrammus aeglefinus) on Georges Bank. Deep-Sea Research II 53(23-24), 2758-2770.

Buesseler, K.O (Ed.). 2001. Ocean biogeochemistry and the carbon cycle; an introduction to the US Joint Global Ocean Flux Study. Oceanography. 14, 5-121.

Choi, J.S., Frank, K.T., Leggett, W.C. \& Drinkwater, K. 2004. Transition to an alternate state in a continental shelf ecosystem, Canadian Journal of Fisheries and Aquatic Sciences, 61, 505-510. 
Christensen, V. \& Pauly, D. (eds.) (1993). Trophic models of aquatic ecosystems. The International Center for Living Aquatic Resources Management (ICLARM) Conference Proceedings, 26, ICLARM, Manila, Philippines.

Cohen, E.B., Grosslein, M.D. \& Sissenwine, M.P. 1982. Energy budget of Georges Bank, Canadian Special Publications in Fisheries and Aquatic Science, 59, 95-107.

DeYoung, B., Werner, F., Chai, F., Megrey, B. \& Monfray, P. 2004. Challenges of modeling ocean basin ecosystems. Science, 304, 1463-1466.

Drinkwater, K.F. 2005. The response of Atlantic cod (Gadus morhua) to future climate change. ICES J. Mar. Sci. 62, 1327-1337.

Frank, K.T., Petrie, B., Choi, J.S. and Leggett, W.C. 2005. Trophic cascades in a formerly cod-dominated ecosystem. Science, 308, 1621-1623.

Friedland, K., Hare, J., Wood, G., Col, L., Buckley, L., Mountain, D., Kane, J., Brodziak, J., Lough, R., Pilskaln, C. 2008. Does the fall phytoplankton bloom control recruitment of Georges Bank haddock, Melanogrammus aeglefinus, through parental condition? Can. J. Fish Aquat. Sci. 65, 1076-1086.

Friedrichs, M.A.M. 2002. Assimilation of JGOFS EqPac and SeaWIFS data into a marine ecosystem model of the central equatorial P acific Ocean. 
Deep-Sea Research. 49, 289-310.

Fulton, E., Smith, A., Johnson, C. 2004. Biogeochemical systems models I: IGBEM a model of marine bay ecosystems. Ecological Modelling. 174, 267-307.

Garrison, L.P., Link, J.S. 2000. Dietary guild structure of the fish community in the north-east United States continental shelf ecosystem. Marine Ecology Progress Series, 202, 231-240.

Gifford, D. J., Collie, J. S., Steele, J. H. 2009. Functional diversity in a marine fish community. ICES Journal of Marine Science, 66, doi:10.1093/icesjms/fsp076

Hall, S.J., Collie, J.S., Duplisea, D.E., Jennings, S., Bravington, M., Link, J. 2006. A length-based multispecies model for evaluating community responses to fishing. Can. J. Fish Aquat. Sci. 63, 1344-1359.

Heath, M.R. 2005. Changes in the structure and function of the North Sea fish food web, 1973-2000, and the impacts of fishing and climate. ICES Journal of Marine Science, 62, 847-868.

Heath, M.R. 2007. The consumption by zooplankton by early life stages of fish in the North Sea. ICES J. Mar. Sci. 64, 1650-1663. 
Hennemuth, R.C., Rockwell, S. (1987). History of fisheries conservation and management. In Georges Bank (ed. R.H. Backus) MIT Press, 430446.

Houde, E.D. 1996. Evaluating stage-specific survival during the early life of fish. In Y. Watanabe, Y. Tamashita and Y. Oozeki (Eds.) Survival strategies in early life stages of marine resources, (pp. 51-66), Balkema, Rotterdam.

Hubbell, S.P. 1997. A unified theory of biogeography and relative species abundance and its application to tropical rain forests and coral reefs. Coral Reefs. 16 Suppl, S9S21.

Kerr, S.R., Dickie, L.M. 2001. The biomass spectrum : a predator-prey theory of aquatic production. Columbia University Press, New York.

Koen-Alonso, M., Yodzis, P. 2005. Multispecies modeling of some components of the marine community of northern and central Patagonia, Argentina. Can. J. Aquat. Sci, 62, 1490-1512

Lehman, C. and Tilman D. 2000. Biodiversity, stability and productivity in competitive communities. Amer. Nat. 156, 534-552.

Lynch, D.R., Lewis, C.V. \& Werner, F. E. 2001. Can Georges Bank larval cod survive on a calanoid diet? Deep-Sea Research II, 48, 609-630. 
Lynch, D.R., McGillicuddy, D., Werner, F. E. 2009. Skill assessment for coupled biological/physical models of marine systems. Journal Marine Systems. 76, 1-3.

Magurran, A,E. 1988 Ecological Diversity and its Measurement. Princeton University Press, Princeton. 179pp.

May, R.M. 1973. Stability and complexity in model ecosystems. Princeton Univ.Press, Princeton. 265pp.

Murawski, S., Steele, J., Taylor, P., Fogarty, M., Sissenwine, M., Ford, M., Suchman C. 2009. Why compare marine ecosystems? ICES Journal Marine Science; doi: 10.1093/icesjms/fsp221

Myers, R.A. (1998). When do environment-recruitment correlations work? Rev Fish Biol and Fisheries. 8, 285-305.

Nicholson, M.D. and Jennings, S. 2004. Testing candidate indicators to support ecosystem-based management: the power of monitoring surveys to detect temporal trends in fish community metrics. ICES J. Mar Sci.61, 35-42.

Plaganyi, E.E. 2007. Models for an ecosystem approach to fisheries. FAO Fisheries Technical Paper 477. 
Plaganyi, E.E. and Butterworth, D.S. 2004. A critical look at the potential of ECOSIM with ECOPATH to assist in practical fisheries management. Afr. J. Mar. Sci. 26, 261-287.

Payne, M.R., Dickey-Collas, M., Nash, R. 2009.Comment on "Does the fall phytoplankton bloom control recruitment of Georges Bank haddock, Melanogrammus aeglefinus, through parental condition?" Canadian Journal of Fisheries and Aquatic Research, 66, 869-872

Pershing, A.J., Greene, C.H., Hannah, C., Sameoto, D., Head, E., Mountain, D.G., Jossi, J., Benfield, M., Reid, P.C.R., Durbin, E.G., 2001. Oceanographic response to climate in the northwest Atlantic. Oceanography 14, 76-82.

Platt,T and Denman, K. 1978. The structure of pelagic marine ecosystems. Rapp. P.V. Reun., Cons. Int. Explor. Mer. 173, 60-65.

Pope, J.G. Rice, J.C., Daan, N., Jennings, S., Gislason, H. 2006. Modelling an exploited marine fish community with 15 parameters - results from a simple sizebased model. ICES J. Mar. Sci. 63, 1029-1044.

Rothschild, B. J. 1986. Dynamics of marine fish populations. Cambridge, Massachusetts: Harvard University Press. 
Sale, P. F. 1977. Maintenance of high diversity in coral reef fish communities. American Naturalist, 111: 337-359.

Sissenwine, M.P., Cohen, E.B., Grosslein, M.D. (1984). Structure of the Georges Bank ecosystem. Rapports et procès-verbaux des réunions / Commission internationale pour l'exploration scientifique de la Mer, 183:243-254.

Steele, J.H. 1974. The structure of marine ecosystems. Harvard University Press. Cambridge, Mass. 128 p.

Steele, J.H. 1985. A comparison of terrestrial and marine ecological systems. Nature 313: $355-358$

Steele, J.H., Collie, J.S. Bisagni, J., Fogarty, M., Gifford, D., Link, M., Sieracki, M., Sullivan, B., Beet, A., Mountain, D., Durbin, E.G., Palka, D. and Stockhausen, W.. 2007. Balancing end-to-end budgets of the Georges Bank ecosystem. Prog. in Oceanogr. 74, 423-448.

Tilman, D. 1999. The ecological consequences of changes in biodiversity. Ecology, $80,1455-1474$.

Vezina, A. R. and T. Platt. 1988. Food web dynamics in the ocean I. Best estimates of flow networks using inverse methods. Mar. Ecol. Prog. Ser. 42, 269-287. 
Walters, c., Christensen, V., Pauly, D. 2005. Structuring dynamic models of exploited systems from trophic mass-balance assessments. Reviews in Fish Biology and Fisheries. 7, 139-172.

Werner, F.E., Perry, R.I., Lough, R.G. and Naimie, C.E. (1996). Trophodynamic and advective influences on Georges Bank larval cod and haddock. Deep Sea Res. II. 43, 1793-1822.

Wiebe, P.H., Beardsley, R.C., Bucklin, A.C. and Mountain, D.G. (Eds) 2001 Coupled biological and physical studies of plankton populations: Georges Bank and related regions. Deep-sea Res. II. 48. 684pp.

Worm, B., Myers, R.A., 2003. Meta-analysis of cod-shrimp interactions reveals topdown control in oceanic food webs. Ecology 84, 162-173.

Yachi, S. and Loreau, M. 1999. Biodiversity and ecosystem productivity: the insurance hypothesis. Proc. Natl. Acad. Sci.96, 1643-1468. 
Table 1.

Assumptions

\begin{tabular}{l|l}
\multicolumn{1}{c|}{ Species-centric approach } & \multicolumn{1}{c}{ Trophic-centric approach } \\
\hline Critical physics_direct action on & Critical physics-indirect effects through \\
planktonic individuals, e.g., copepods, fish & processes of nutrient supply \& new \\
larvae & production \\
Critical ecology_population dynamics at & Critical ecology_energetics of trophic \\
critical life stages, e.g., copepod diapause & groups and fluxes between groups
\end{tabular}

\section{Trade-offs}

\begin{tabular}{l|l}
\multicolumn{1}{c|}{ Species-centric approach } & \multicolumn{1}{c}{ Trophic-centric approach } \\
\hline Physical complexity_detailed dynamics & Trophic complexity_food webs containing \\
for regions with complex topography & many groups from microbes to whales \\
Trophic simplicity_spatial demography of & Physical simplicity_linear steady states \\
one species or one life history stage & averaged over time and space
\end{tabular}


Table and Figure captions.

Table 1. Assumptions and trade-offs of the species-centric and trophic-centric modeling approaches.

Figure 1. Georges Bank in the northwest Atlantic showing the approximate location of A, eggs; B, larvae; and C, pelagic juveniles of cod and haddock in response to circulation between the tidal (red line) and shelf edge (dashed line) fronts. Adapted from Lough \& Manning (2001).

Figure 2. (a) Calculated total food requirement of fish on Georges Bank (ktons.year ${ }^{-1}$ ) compared with the total commercial fish catch (Hennemuth and Rockwell, 1987; M. Fogarty, pers.comm.) (b) Fraction of the food intake by fish contributed by benthic fauna. (c) Shannon Index of evenness (McGurran, 1988; Gifford et al, 2009). (d) Biomass of dominant planktivores. (e) Biomass of dominant piscivores (Steele et al 2007).

Figure 3. Georges Bank food web showing the components used in Collie et al (2009). Solid arrows represent fluxes. The input $\mathrm{NO}_{3}$ drives the microbial food web including recycling of nitrogen as $\mathrm{NH}_{4}$ (dashed lines). Dotted lines are physical losses.

Figure 4. Fish population biomass allocated to size and diet categories (a) percentage biomass in three size classes and (b) percentage biomass in three feeding guilds. 


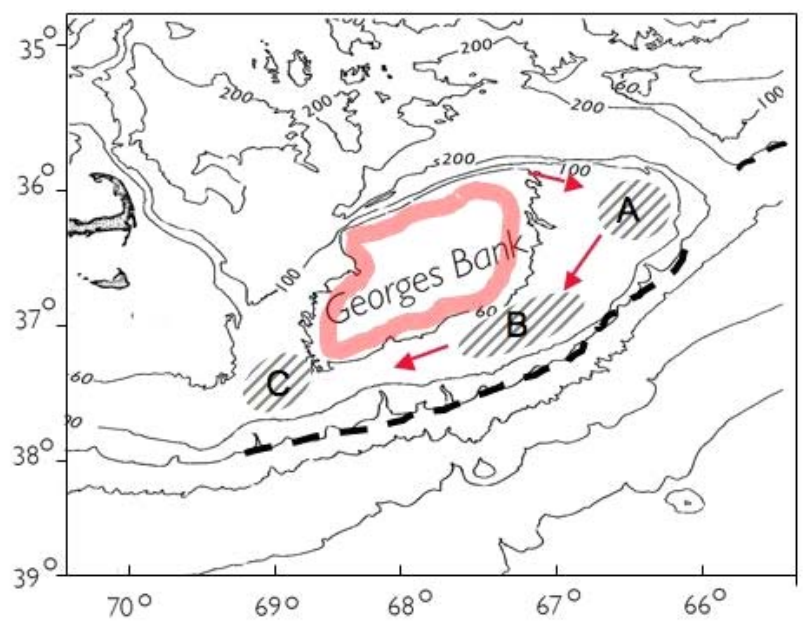

Fig. 1. 

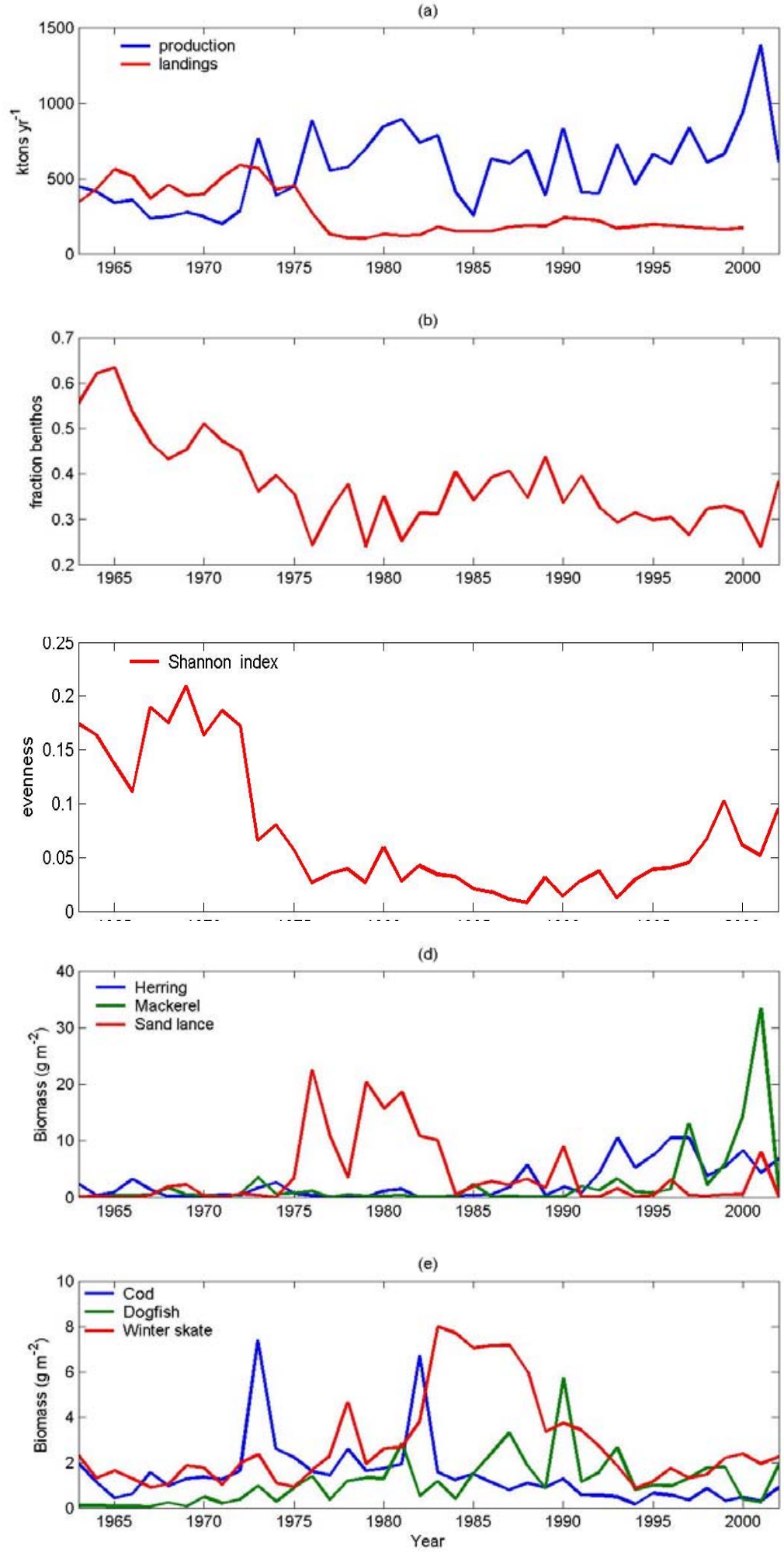

Figure 2. 


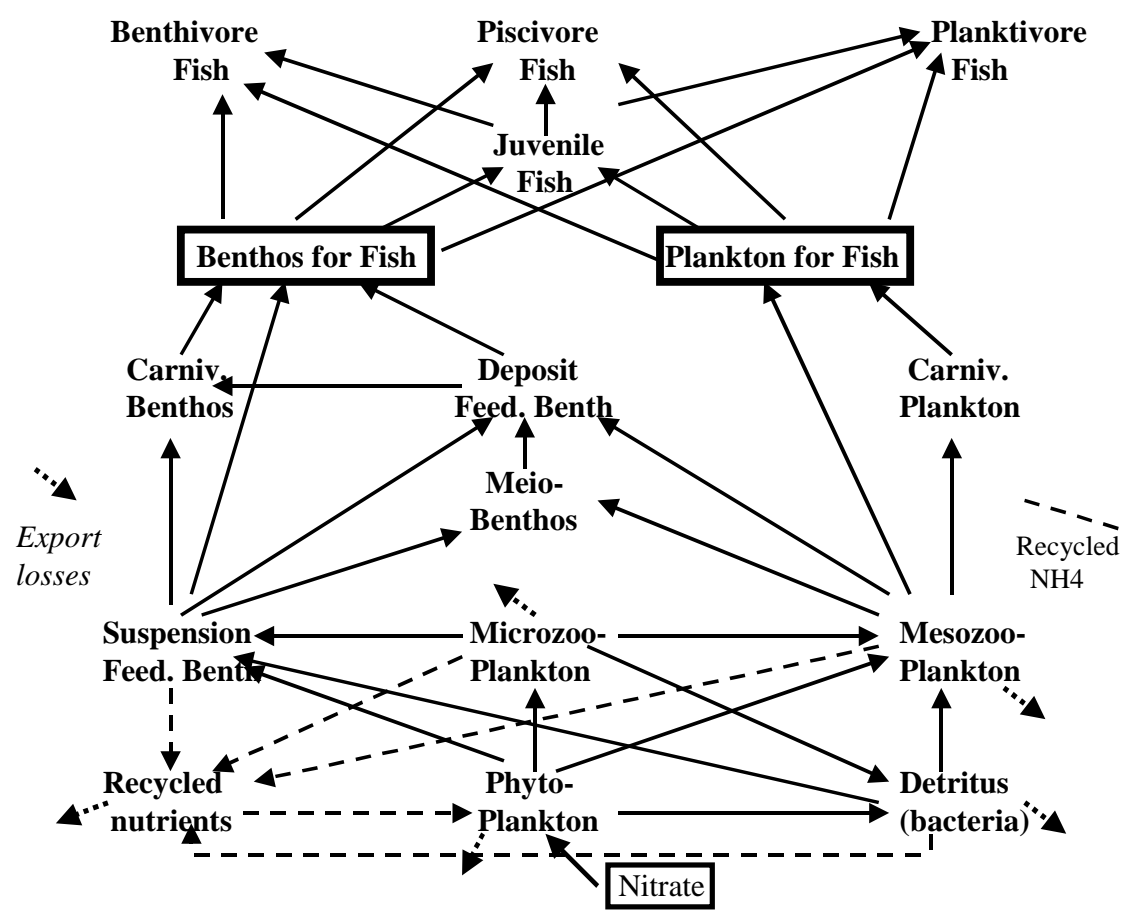

Fig. 3
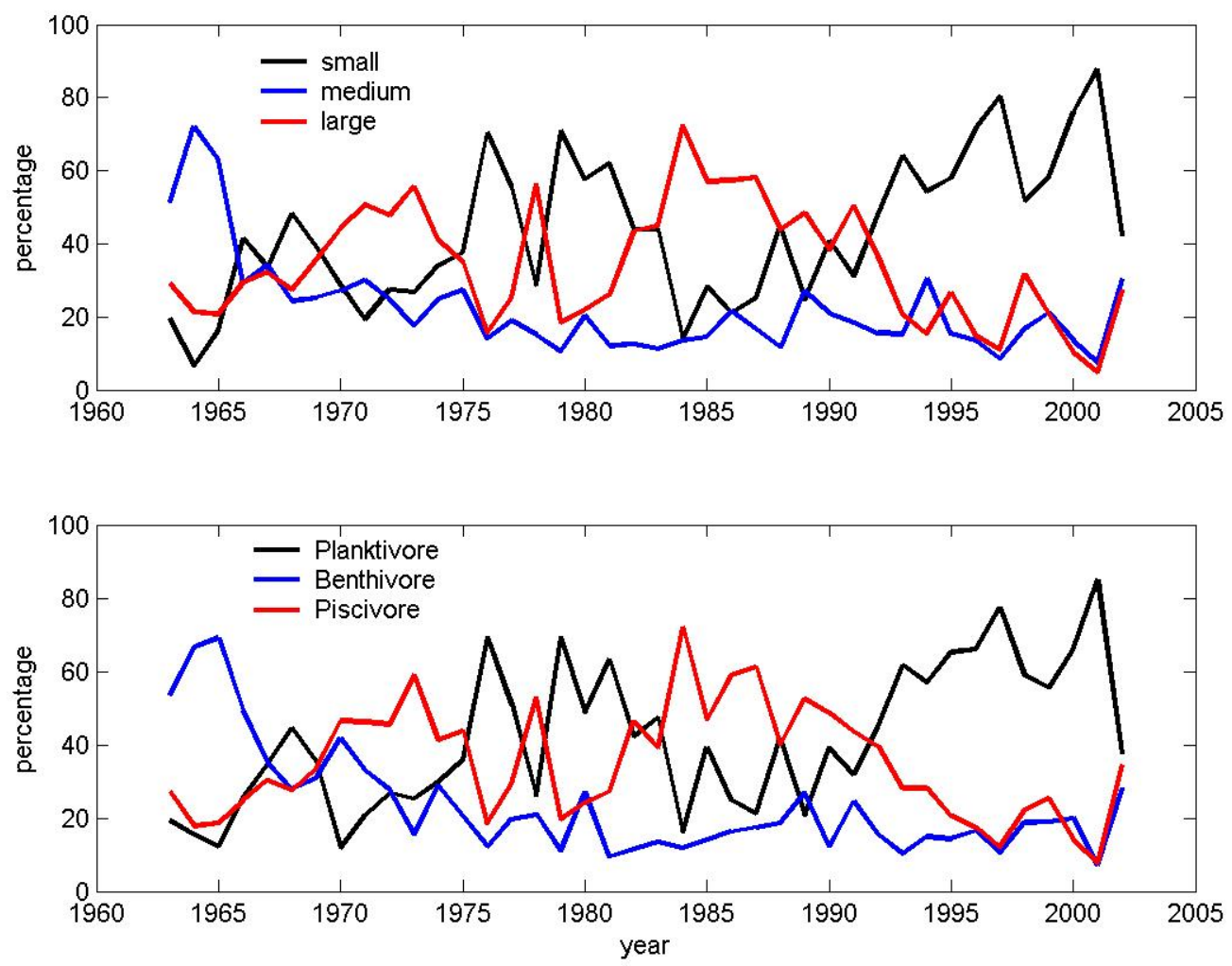

Figure 4. 
